\title{
Administration of Drugs Known to Inhibit P-Glycoprotein Increases Brain Bilirubin and Alters the Regional Distribution of Bilirubin in Rat Brain
}

\author{
ERIK HANKØ, STEVE TOMMARELLO, JON F. WATCHKO, AND THOR W. R. HANSEN
}

Department of Pediatrics, Rikshospitalet, N-0027 Oslo, and Neurochemical Laboratory, University of Oslo, Pb 1115, N-0317 Oslo, Norway [E.H., T.W.R.H.], Department of Anesthesiology and Critical Care Medicine, Children's Hospital, University of Pittsburgh School of Medicine [S.T., T.W.R.H.], and Department of Pediatrics, Magee-Womens Research Institute, University of Pittsburgh [J.F.W.], Pittsburgh, Pennsylvania 15213, U.S.A.

\begin{abstract}
P-Glycoprotein (P-gp) is an ATP-dependent integral plasma membrane efflux pump, expressed in abundance in brain capillary endothelial cells and astrocytes. P-gp contributes to the blood-brain barrier in limiting the influx and retention of a variety of lipophilic compounds, including unconjugated bilirubin. Several drugs block P-gp function and thereby enhance intracellular accumulation of P-gp substrates. In this study we proposed that pretreatment with drugs known to inhibit P-gp function in clinically relevant doses would alter the uptake of bilirubin in the brain of 32- to 36-d-old rats. In the first arm of the study, the animals received pretreatment with an i.v. infusion of either propanolol, erythromycin, verapamil, ceftriaxone, rifampin, or saline, 10 min before an i.v. bolus of $50 \mathrm{mg} / \mathrm{kg}$ bilirubin was given. Except for the erythromycin-treated rats, all treatment groups had significantly higher brain-to-serum bilirubin ratios than control animals ( $p<0.05$, Welch's $t$ test). In the second arm of the study, treatment with either ceftriaxone or rifampin or saline i.v. preceded a $50 \mathrm{mg} / \mathrm{kg}$ i.v. bolus of radioactive
\end{abstract}

\section{ABSTRACT}

bilirubin. Analysis of seven different brain regions by scintillation counting showed that the distribution patterns differed significantly between the study groups $(p<0.001$, ANOVA), however, not in accordance with a kernicteric staining pattern. Because of limited knowledge of expression and function of P-gp and other membrane transport proteins in the newborn, the implications of this study remain to be seen. We speculate that drugs known to inhibit P-gp function may increase the risk of bilirubin encephalopathy in the hyperbilirubinemic infant. (Pediatr Res 54: 441-445, 2003)

BBB, blood-brain barrier

\section{Abbreviations}

P-gp, P-glycoprotein

UCB, unconjugated bilirubin

MRP, non-P-gp transporter

OATp, non-P-gp transporter
Increased bilirubin entry into brain is presumably associated with increased risk of toxicity. Energy-independent passage to the CNS is restricted by the BBB and is limited to lipid-soluble substances (1). UCB, like several other lipophilic or amphipathic compounds known to cross the BBB, evinces a surprisingly low accumulation in the $\operatorname{CNS}(2,3)$. This phenomenon is incompletely understood, but many of these compounds are

Received February 22, 2001; accepted January 28, 2003.

Correspondence: Thor Willy Ruud Hansen, M.D., Ph.D., Section on Neonatology, Department of Pediatrics, Rikshospitalet, N-0027 Oslo, Norway; e-mail: t.w.r.hansen@klinmed.uio.no

Supported by grants from The University Anesthesia and Critical Care Medical Foundation, Pittsburgh, by Children's Hospital of Pittsburgh, and by the Nansen Fund.

DOI: 10.1203/01.PDR.0000085169.87948.B6 substrates for membrane transport proteins that regulate the entry and efflux of substrates across cell membranes $(2,4)$. P-gp, a member of the ATP-binding cassette superfamily of membrane transporters, is the best-studied member of the membrane transport proteins. There is, however, growing evidence that non-P-gp transporters like MRP and OATp have potential for regulation of drug entry and expulsion across the $\mathrm{BBB}$ and the choroid plexus $(5,6)$.

Membrane transport proteins are expressed in a variety of normal tissues. The gene encoding for P-gp belongs to the $m d r$ multigene family, consisting of two highly homologous genes, $m d r 1$ and $m d r 2$, albeit only $m d r 1$ seems to be involved in the expulsion of xenobiotics $(7,8)$. Studies on $m d r 1$-null mutant mice devoid of BBB P-gp have shown enhanced uptake of a 
variety of lipophilic xenobiotics in brain $(9,10)$. Watchko et al. (11) found that brain bilirubin content was almost 2-fold higher in these mutant mice compared with wild-type animals after an i.v. infusion of bilirubin. Brain bilirubin clearance did not differ between the groups, suggesting that the increased bilirubin content was caused by increased influx and that, hence, UCB is a substrate for P-gp at the BBB.

P-gp limits the entry of several cytotoxic drugs into cells, and is associated with multidrug resistance in cancer therapy $(12,13)$. Consequently, inhibition of P-gp activity to obtain higher intracellular concentrations of cytotoxic drugs has been a major issue in cancer research $(12,13)$. Drugs known to inhibit P-gp function, such as cortisol $(14,15)$ or erythromycin (16), are used in neonatal medicine. It was not known whether the administration of P-gp-inhibiting agents to hyperbilirubinemic infants influences bilirubin entry into brain. In the present study we hypothesized that treatment with drugs known to inhibit P-gp function would modify bilirubin entry into the brain of young adult rats. In the first arm of the study, whole-brain bilirubin entry was analyzed after administration of P-gp blockers followed by an i.v. infusion of bilirubin. Because of their widespread use in clinical medicine and documented inhibition of P-gp, ceftriaxone (17), erythromycin (16), rifampin (18), verapamil $(19,20)$, and propanolol $(21,22)$ were chosen. The classic bilirubin-induced brain damage, kernicterus, is localized in the basal ganglia, cerebellum, and cranial nerve nuclei (23). The mechanism(s) behind the preference for these brain regions is not known. In the second arm of the study, two of the drugs from the first study arm, rifampin and ceftriaxone, were chosen to study changes in the regional distribution pattern of bilirubin within the brain.

\section{METHODS}

Materials. These experiments were carried out in part in the laboratories of the Department of Anesthesia and Critical Care Medicine, University of Pittsburgh, PA, U.S.A., and in the Neurochemical Laboratory, University of Oslo, Norway. The study was approved through the appropriate review procedures for animal research at both institutions.

Sprague-Dawley rats aged 32-36 d of both sexes were obtained from Hilltop Lab Animals Inc, Scottdale, PA, U.S.A., and from Dyrlæge Møllegaards Avlslaboratorium, Ll Skensved, Denmark. $\left[{ }^{3} \mathrm{H}\right]$ Bilirubin was synthesized by Moravek Biochemical, Inc, Brea, CA, U.S.A. The specific activity was greater than $50 \mathrm{mCi} / \mathrm{mmol}$ and the purity was greater than $90 \%$ as determined by HPLC by the manufacturer. Nonradioactive bilirubin and albumin were from Sigma Chemical Co, St. Louis, MO, U.S.A. Other reagents and drugs were from standard commercial suppliers.

Preparation of the reagents. Unlabeled bilirubin was dissolved in $0.1 \mathrm{M} \mathrm{NaOH}$, stabilized with BSA (molar ratio bilirubin:albumin $(\mathrm{B}: \mathrm{A})=14)$, and diluted with Krebs-Ringer buffer, $\mathrm{pH} 7.4$, to a concentration of $3 \mathrm{mg} / \mathrm{mL}$ (final $\mathrm{pH}, 7.8$ ). For the studies involving regional distribution radioactive bilirubin was added to give each rat $20 \mu \mathrm{Ci}$ in a bilirubin bolus of $50 \mathrm{mg} / \mathrm{kg}$ i.v. during a period of $5 \mathrm{~min}$, whereas in the studies involving whole-brain uptake only unlabeled bilirubin was used. Bilirubin- containing syringes and tubing were wrapped in tin foil to reduce photodecomposition of bilirubin.

Preparation of the rat model. On the day of the experiment the rats were weighed, and then anesthetized with a s.c. injection of $1-2 \mathrm{~mL} / \mathrm{kg}$ of a mixture of fentanyl, droperidol, and midazolam $(0.025,1.25$, and $0.625 \mathrm{mg} / \mathrm{mL}$, respectively) as previously described (24). Anesthesia was maintained throughout the study by supplementary injections as needed. An i.v. catheter was placed in a dorsal foot vein for infusions.

There were two arms in the study, the first involving bilirubin entry into whole brain, and the second involving regional distribution of bilirubin in brain. In both arms the study drug was administered first, followed by a 10-min interval, after which the bilirubin bolus was given for $5 \mathrm{~min}$, as described above. Ten minutes after the start of the bilirubin infusion, blood samples were obtained by cardiac puncture, and the animals were killed with an i.v. dose of pentobarbital $(100 \mathrm{mg} / \mathrm{kg})$.

In the study arm involving whole-brain uptake of bilirubin the following P-gp-inhibiting drugs and doses were used: verapamil ( $1 \mathrm{mg} / \mathrm{kg} ; n=11)$, propanolol $(0.15 \mathrm{mg} / \mathrm{kg} ; n=7)$, ceftriaxone $(100 \mathrm{mg} / \mathrm{kg} ; n=7)$, erythromycin $(10 \mathrm{mg} / \mathrm{kg} ; n=$ $6)$, or rifampin (10 mg $/ \mathrm{kg} ; n=6)$. Control rats $(n=12)$ were pretreated with equivalent volumes of saline. In the study arm involving regional distribution, rifampin $(n=10)$, ceftriaxone $(n=10)$, and saline $(n=10)$ were used in the same doses as in the first study arm.

Analyses in brain tissue and serum. Immediately after sacrifice of the rat the chest was opened, the ascending aorta was cannulated, the descending aorta was clamped, the jugular veins were transected, and the cerebral vasculature was flushed in situ with $120 \mathrm{~mL}$ of ice-cold saline at a rate of $25 \mathrm{~mL} / \mathrm{min}$. The brain was removed and carefully stripped of meningeal coverings and surface vessels.

In the first arm of the study the brain was then weighed, and the bilirubin content was determined by acid chloroform extraction (25). In the second arm of the study the brains were dissected into seven regions as described by Glowinski and Iversen (26). Each region was then weighed, and the content of bilirubin was determined by scintillation counting as described previously (24). Serum bilirubin (obtained at sacrifice) was analyzed by the diazo method (27). Serum unbound bilirubin was analyzed with the peroxidase method (28).

Data handling. Data for each experimental group in the first study arm were compared with control animals using unpaired $t$ test. Because of heterogeneity of variance, Welch's $t$ test was chosen. The serum bilirubin values differed significantly from those of control rats in some of the treatment groups in the first arm of the study. As this might conceivably have influenced brain bilirubin content, a brain-to-serum bilirubin ratio $(\times 1000)$ was calculated for each animal and used in the subsequent calculations as previously described $(29,30)$. In the second arm of the study data regarding regional distribution were compared with ANOVA, followed by the Tukey-Kramer multiple comparisons test. The level of significance of $p<$ 0.05 was chosen. Data are reported as mean \pm SD. 


\section{RESULTS}

Effects of pretreatment with drugs known to inhibit P-gp function on bilirubin entry into whole brain. The mean serum bilirubin values in the first arm of the study are shown in Table 1. The mean serum bilirubin value for the verapamil-treated rats was significantly higher than for the control rats and the ceftriaxone-treated animals. This phenomenon was most likely related to serendipitous experimental variability. Unbound serum bilirubin values did not differ among the groups (overall mean $\pm \mathrm{SD}, 36 \pm 18 \mathrm{nmol} / \mathrm{L}$ ). To eliminate a possible systematic error a brain-to-serum bilirubin ratio was calculated. These ratios are shown in Figure 1. With the exception of the group that received erythromycin, all the groups had significantly higher brain-to-serum bilirubin ratios ranging from $143 \%$ (verapamil) to $236 \%$ (ceftriaxone) compared with control rats.

Effects of pretreatment with drugs known to inhibit P-gp function on bilirubin entry into brain regions. The mechanism(s) behind the preference for basal ganglia, cerebellum, and cranial nerve nuclei as seen in kernicterus is not known. In the second arm of the study, two of the drugs from the first study arm, rifampin and ceftriaxone, were chosen to elucidate possible changes in the regional distribution pattern of bilirubin within the brain. In this arm of the study serum bilirubin values did not differ significantly among the groups (Table 2). Therefore the brain bilirubin concentrations were compared directly using ANOVA. The concentrations differed significantly among brain regions in all three study groups $(p<0.0001$; Fig. $2)$. Although the pattern of distribution was similar in the control rats versus the ceftriaxone-treated rats, in that both groups had a significantly higher bilirubin concentration in the cerebellum, the rifampin-treated rats differed in having a significantly lower bilirubin concentration in the cerebral cortex.

\section{DISCUSSION}

The principal findings of this study are that therapeutic doses of several drugs known to inhibit P-gp function 1) enhance bilirubin entry into the brain and 2) may impact on the mechanism for localization of bilirubin in rat brain. P-gp-inhibiting drugs appear to have a similar effect on brain bilirubin entry as that previously found in mdrla (-/-) P-gp-deficient mice. Other studies have also found that inhibition of P-gp increases the brain accumulation of P-gp substrates. In one study the P-gp inhibitor cyclosporin A administered intraperitoneally increased brain concentrations of ivermectin 2.5-fold in adult female rats (31). In an in vivo microdialysis study in freely moving young adult rats, cyclosporin A induced a 3-fold increase in the cortical concentration of rhodamine 123 (32).

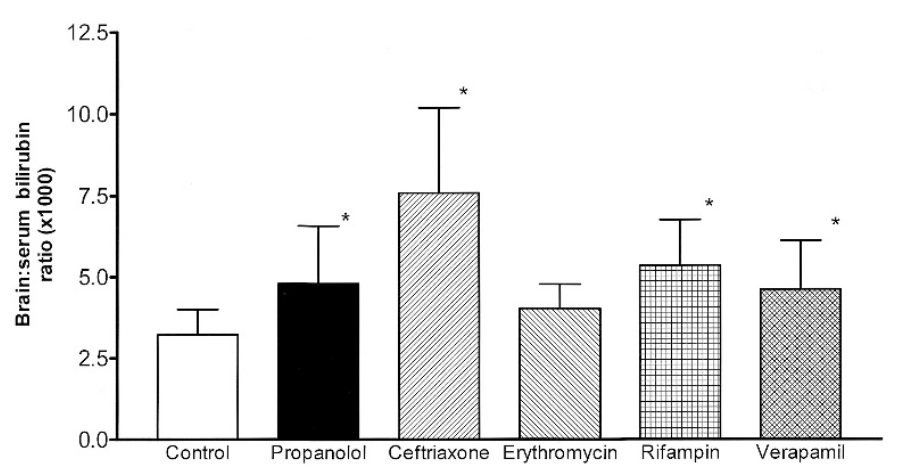

Figure 1. Effect of P-gp-inhibiting drugs on bilirubin entry into whole brain of young adult rats. Immediately after sacrifice of the animals the entire brain was removed and weighed, and the bilirubin content was determined by acid chloroform extraction. For each animal a brain-to-serum bilirubin ratio was calculated. Data are given as brain-to-serum bilirubin ratio $\times 1000$, and represent mean $\pm \mathrm{SD},{ }^{*} p<0.05$ vs control. The data were analyzed by Welch's $t$ test.

Table 2. Serum bilirubin values at sacrifice in rats examined for the regional distribution of bilirubin in brain regions*

\begin{tabular}{cccc}
\hline & $\begin{array}{c}\text { Control } \\
(n=10)\end{array}$ & $\begin{array}{c}\text { Ceftriaxone } \\
(n=10)\end{array}$ & $\begin{array}{c}\text { Rifampin } \\
(n=10)\end{array}$ \\
\hline Mean \pm SD & $618 \pm 73$ & $535 \pm 43$ & $586 \pm 104$ \\
\hline
\end{tabular}

* The study drug was administered i.v., followed by a 10-min interval, after which labeled bilirubin was given for $5 \mathrm{~min}$. Blood samples were obtained by cardiac puncture immediately before sacrifice of the animals 10 min later. Serum bilirubin was analyzed by diazo method and reported as $\mu \mathrm{mol} / \mathrm{L}$. The groups were compared using ANOVA (NS).

In the 1950s sulfisoxazole was blamed for numerous cases of kernicterus (33). This was subsequently shown to be caused by the ability of sulfisoxazole to displace bilirubin from its binding to albumin. Ceftriaxone is both a P-gp inhibitor and a highly potent displacer of bilirubin. As the brain-to-serum ratio bilirubin in ceftriaxone-treated animals increased relatively more than in former studies on $m d r l$-null mutant mice devoid of P-gp (11), the bilirubin-displacing property of the drug apparently had an additive impact on bilirubin entry into brain. However, pretreatment with agents without a significant bilirubin-displacing effect increased bilirubin accumulation in whole brain by $24 \%$ (erythromycin, NS) to $66 \%$ (rifampin) (34). This increase corresponds to the increase in brain bilirubin induced by other known risk factors such as hyperosmolarity or hypercapnia. In one study on a comparable group of young adult rats induction of hyperosmolarity or hypercapnia increased bilirubin uptake in whole brain by 39 and $70 \%$, respectively (30).

The mechanism behind the preference for the basal ganglia, cerebellum, and cranial nerve nuclei in kernicterus is not

Table 1. Serum bilirubin values at sacrifice in rats examined for the uptake of bilirubin in whole brain*

\begin{tabular}{|c|c|c|c|c|c|c|}
\hline & $\begin{array}{c}\text { Control } \\
(n=12)\end{array}$ & $\begin{array}{c}\text { Verapamil } \\
(n=11)\end{array}$ & $\begin{array}{l}\text { Propanolol } \\
\quad(n=7)\end{array}$ & $\begin{array}{l}\text { Ceftriaxone } \\
\quad(n=7)\end{array}$ & $\begin{array}{l}\text { Erythromycin } \\
\quad(n=6)\end{array}$ & $\begin{array}{c}\text { Rifampin } \\
(n=6)\end{array}$ \\
\hline Mean \pm SD & $495 \pm 62$ & $609 \pm 57$ & $537 \pm 108$ & $\begin{array}{c}497 \pm 75 \\
0.95\end{array}$ & $597 \pm 37$ & $585 \pm 74$ \\
\hline
\end{tabular}

* The study drug was administered i.v., followed by a 10-min interval, after which bilirubin $(50 \mathrm{mg} / \mathrm{kg}$, i.v.) was given for 5 min. Blood samples were obtained by cardiac puncture immediately before sacrifice of the animals $10 \mathrm{~min}$ later. Serum bilirubin was analyzed by the diazo method, and expressed as $\mu \mathrm{mol} / \mathrm{L}$. The data were analyzed by Welch's $t$ test, and each group was contrasted separately with controls. 


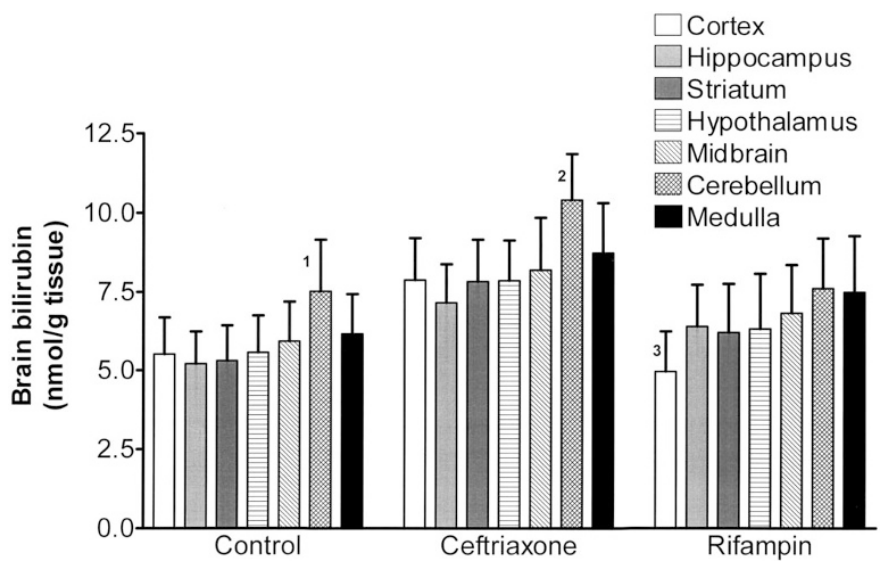

Figure 2. Effect of P-gp-inhibiting drugs on bilirubin entry into brain regions of young adult rats. Immediately after sacrifice of the animals the brains were dissected into seven regions, each region was then weighed, and the content of labeled bilirubin was determined by scintillation counting. Data are expressed as nanomoles of bilirubin per gram of brain tissue and represent mean $\pm \mathrm{SD}$. The data were analyzed by ANOVA. Between groups $p<0.0001$; within groups $p<0.0001 ; 1, p<0.05 v s$ all regions except midbrain and medulla; $2, p<0.05 v s$ all regions except medulla; $3, p<0.01$ vs cerebellum and medulla.

known (23). In the present study significant differences in the regional entry of bilirubin were found for the cerebellum in the control rats and ceftriaxone-treated rats and for the cortex cerebri in the rifampin-treated rats. For all other areas of the brain bilirubin content was equally enhanced. Few studies have investigated changes in distribution patterns within the brain as a result of P-gp-inhibiting drugs. In two studies by Drion et al. $(35,36)$ pretreatment with the second-generation P-gp blocker PSC-833 or verapamil increased the distribution volume of the cytostatic drug colchicine 8- and 4-fold, respectively, in eight gray areas of the brain, but distribution volumes were similarly enhanced in all brain areas. A possible explanation for the modest impact of P-gp-inhibiting drugs may be that P-gp was unequally saturated in the different areas of the brain. The significance of the altered distribution in the present study is uncertain. Factors other than P-gp may play a role as regards the distribution of bilirubin within the brain, but the specific nature of these factors is unknown. Thus, neither hypercapnia nor hyperosmolarity induced regional differences in bilirubin uptake in young adult rats (30). Also, no differences in the clearance of bilirubin from different brain regions could be detected in young adult rats (24).

The relative contribution of $\mathrm{P}$-gp and non-P-gp processes to drug efflux is largely unknown. This is mainly because of limited knowledge of the distribution and function of membrane transporter proteins at the BBB. Furthermore, there seems to be a considerable overlap in substrate specificity among different transporters and a lack of selective inhibitors. There is, for example, evidence that the quinolone antibacterial agent HSR-903 is a substrate both for P-gp and an anionsensitive efflux transport mechanism at the BBB (37). Further, both P-gp and OATp2 in rodents and OATpA in the human brain have proven to be involved in the transport of opioid peptides across the $\mathrm{BBB}(10,38)$. UCB is a substrate for MRP in human choriocarcinoma cell lines (39), and OATp2 in liver cells (40). However, transport of UCB by these transporters at the BBB has to our knowledge not been studied. Of the P-gp inhibitors used in the present study, both verapamil and rifampin have been shown to interfere with MRP function (41, 42). More studies of the substrate properties of OATp and MRP at the BBB, and the identification of other membrane transport proteins for which UCB may be a substrate at the $\mathrm{BBB}$, are eagerly awaited.

Although little is known about the ontogeny of MRP and OATp in the brain, brain P-gp expression has been shown to be limited in early fetal life and seems to undergo a consistent up-regulation perinatally. In the human brain P-gp is expressed in capillary endothelial cells, astrocytes, and choroid plexus epithelium by 23 wk gestation (43). At term the distribution pattern was similar to the one found in adult brain, although with markedly less density. In mice, brain P-gp is expressed from embryonic $\mathrm{d} 16$, and adult levels were reached by postnatal d 21 (44). In a recent study in the rat brain P-gp was not detected until postnatal $\mathrm{d} 7$ and was then found mainly in brain capillary endothelial cells in the cerebellum, the hippocampus, and the frontal cortex, reaching adult levels from postnatal d 28 (45). Consequently, the animals of the present study (age, 32-36 d) had all reached adult levels of P-gp expression in the brain. Caution should be taken in extrapolating the findings of the present study to newborns. The functional impact of developmental changes of P-gp and other membrane transport proteins at the BBB in the first weeks of life are not known.

\section{CONCLUSIONS}

In conclusion we have shown that administration of therapeutic doses of drugs with modest P-gp-inhibiting properties enhances bilirubin entry into the brain of young adult rats and may have an impact on the distribution pattern of bilirubin in the brain. The finding that drugs without significant bilirubindisplacing properties may enhance bilirubin entry into brain is novel. Because of the limited knowledge of the ontogeny of membrane transport proteins, the overlap in substrate specificity between different transporters, and a lack of selective inhibitors, it is at present not clear whether the drugs used in the present study inhibited P-gp exclusively. Further studies are warranted to clarify the implications of our findings in newborns.

\section{REFERENCES}

1. Pardridge WM 1998 CNS drug design based on principles of blood-brain barrier transport. J Neurochem 70:1781-1792

2. Habgood MD, Begley DJ, Abbott NJ 2000 Determinants of passive drug entry into the central nervous system. Cell Mol Neurobiol 20:231-253

3. Jette L, Murphy GF, Leclerc JM, Beliveau R 1995 Interaction of drugs with P-glycoprotein in brain capillaries. Biochem Pharmacol 50:1701-1709

4. Hendrikse NH, de Vries EG, Eriks-Fluks L, van der Graaf WT, Hospers GA, Willemsen AT, Vaalburg W, Franssen EJ 1999 A new in vivo method to study P-glycoprotein transport in tumors and the blood-brain barrier. Cancer Res 59:24112416

5. Tamai I, Tsuji A 2000 Transporter-mediated permeation of drugs across the bloodbrain barrier. J Pharm Sci 89:1371-1388

6. Bart J, Groen HJ, Hendrikse NH, van der Graaf WT, Vaalburg W, de Vries EG 2000 The blood-brain barrier and oncology: new insights into function and modulation. Cancer Treat Rev 26:449-462

7. Germann UA, Pastan I, Gottesman MM 1993 P-glycoproteins: mediators of multidrug resistance. Semin Cell Biol 4:63-76

8. Pastan I, Gottesman MM, Ueda K, Lovelace E, Rutherford AV, Willingham MC 1988 A retrovirus carrying an MDR1 cDNA confers multidrug resistance and polarized 
expression of P-glycoprotein in MDCK cells. Proc Natl Acad Sci USA 85:44864490

9. Schinkel AH, Smit JJ, van Tellingen O, Beijnen JH, Wagenaar E, van Deemter L, Mo CA, van der Valk MA, Robanus-Maandag EC, te Riele HP 1994 Disruption of the mouse mdrla P-glycoprotein gene leads to a deficiency in the blood-brain barrier and to increased sensitivity to drugs. Cell 77:491-502

10. Schinkel AH, Wagenaar E, Mol CA, van Deemter L 1996 P-glycoprotein in the blood-brain barrier of mice influences the brain penetration and pharmacological activity of many drugs. J Clin Invest 97:2517-2524

11. Watchko JF, Daood MJ, Hansen TW 1998 Brain bilirubin content is increased in P-glycoprotein-deficient transgenic null mutant mice. Pediatr Res 44:763-766

12. Ford JM, Hait WN 1990 Pharmacology of drugs that alter multidrug resistance in cancer. Pharmacol Rev 42:155-199

13. Ford JM, Hait WN 1993 Pharmacologic circumvention of multidrug resistance. Cytotechnology 12:171-212

14. Yang C-PH, DePinho SG, Greenberger LM, Arceci RJ, Horwitz SB 1989 Progesterone interacts with P-glycoprotein in multidrug-resistant cells and in the endometrium of gravid uterus. J Biol Chem 264:782-788

15. van Kalken CK, Broxterman HJ, Pinedo HM, Feller N, Dekker H, Lankelma J, Giaccone G 1993 Cortisol is transported by the multidrug resistance gene product P-glycoprotein. Br J Cancer 67:284-289

16. Hofsli E, Nissen-Meyer J 1989 Effect of erythromycin and tumour necrosis factor on the drug resistance of multidrug-resistant cells: reversal of drug resistance by erythromycin. Int J Cancer 43:520-525

17. Gosland MP, Lum BL, Sikic BI 1989 Reversal by cefoperazone of resistance to etoposide, doxorubicin, and vinblastine in multidrug resistant human sarcoma cells. Cancer Res 49:6901-6905

18. Fardel O, Lecureur V, Loyer P, Guillouzo A 1995 Rifampicin enhances anti-cancer drug accumulation and activity in multidrug-resistant cells. Biochem Pharmacol 49:1255-1260

19. Tsuruo T, Iida H, Yamashiro M, Tsukagoshi S, Sakurai Y 1982 Enhancement of vincristine- and adriamycin-induced cytotoxicity by verapamil in P388 leukemia and its sublines resistant to vincristine and adriamycin. Biochem Pharmacol 31:31383140

20. Tsuruo T, Iida H, Naganuma K, Tsukagoshi S, Sakurai Y 1983 Promotion by verapamil of vincristine responsiveness in tumor cell lines inherently resistant to the drug. Cancer Res 43:808-813

21. Kwon Y, Kamath AV, Morris ME 1996 Inhibitors of P-glycoprotein-mediated daunomycin transport in rat liver canalicular membrane vesicles. J Pharm Sci 85:935-939

22. Wigler PW, Patterson FK 1994 Reversal agent inhibition of the multidrug resistance pump in human leukemic lymphoblasts. Biochim Biophys Acta 1189:1-6

23. Volpe JJ 2000 Neurology of the Newborn, 4th ed. Saunders, Philadelphia, pp 521-546

24. Hansen TW 1996 Bilirubin entry into and clearance from rat brain during hypercarbia and hyperosmolality. Pediatr Res 39:72-76

25. Bratlid D, Winsnes A 1971 Determination of conjugated and unconjugated bilirubin by methods based on direct spectrophotometry and chloroform-extraction: a reappraisal. Scand J Clin Lab Invest 28:41-48

26. Glowinski J, Iversen LL 1966 Regional studies of catecholamines in the rat brain. I. The disposition of $\left[{ }^{3} \mathrm{H}\right]$ norepinephrine, $\left[{ }^{3} \mathrm{H}\right]$ dopamine and $\left[{ }^{3} \mathrm{H}\right]$ dopa in various regions of the brain. J Neurochem 13:655-669

27. Martinek RG 1966 Improved micro-method for determination of serum bilirubin. Clin Chim Acta 13:161-170
28. Jacobsen J, Wennberg RP 1974 Determination of unbound bilirubin in the serum of newborns. Clin Chem 20:783

29. de Lange EC, de Bock G, Schinkel AH, de Boer AG, Breimer DD 1998 BBB transport and P-glycoprotein functionality using MDR1A $(-/-)$ and wild-type mice. Total brain versus microdialysis concentration profiles of rhodamine-123. Pharm Res 15:1657-1665

30. Hansen TW, Oyasaeter S, Stiris T, Bratlid D 1989 Effects of sulfisoxazole, hypercarbia, and hyperosmolality on entry of bilirubin and albumin into brain regions in young rats. Biol Neonate 56:22-30

31. Marques-Santos LF, Bernardo RR, de Paula EF, Rumjanek VM 1999 Cyclosporine A and trifluoperazine, two resistance modulating agents, increase ivermectin neurotoxicity in mice. Pharmacol Toxicol 84:125-129

32. Wang Q, Yang H, Miller DW, Elmquist WF 1995 Effect of the P-glycoprotein inhibitor, cyclosporine A, on the distribution of rhodamine-123 to the brain: an in vivo microdialysis study in freely moving rats. Biochem Biophys Res Commun 211:719726

33. Silverman WA, Andersen DH, Blanc WA, Crozier DN 1956 A difference in mortality rate and incidence of kernicterus among premature infants allotted to two prophylactic antibacterial regimens. Pediatrics 18:614-625

34. Robertson A, Karp W, Brodersen R 1991 Bilirubin displacing effect of drugs used in neonatology. Acta Paediatr Scand 80:1119-1127

35. Drion N, Lemaire M, Lefauconnier JM, Scherrmann JM 1996 Role of P-glycoprotein in the blood-brain transport of colchicine and vinblastine. J Neurochem 67:16881693

36. Drion N, Risede P, Cholet N, Chanez C, Scherrmann JM 1997 Role of P-170 glycoprotein in colchicine brain uptake. J Neurosci Res 49:80-88

37. Murata M, Tamai I, Kato H, Nagata O, Kato H, Tsuji A 1999 Efflux transport of a new quinolone antibacterial agent, HSR-903, across the blood-brain barrier. J Pharmacol Exp Ther 290:51-57

38. Gao B, Hagenbuch B, Kullak-Ublick GA, Benke D, Aguzzi A, Meier PJ 2000 Organic anion-transporting polypeptides mediate transport of opioid peptides across blood-brain barrier. J Pharmacol Exp Ther 294:73-79

39. Pascolo L, Fernetti C, Garcia-Mediavilla MV, Ostrow JD, Tiribelli C 2001 Mechanisms for the transport of unconjugated bilirubin in human trophoblastic BeWo cells. FEBS Lett 495:94-99

40. Cui Y, Konig J, Leier I, Buchholz U, Keppler D 2001 Hepatic uptake of bilirubin and its conjugates by the human organic anion transporter SLC21A6. J Biol Chem 276:9626-9630

41. Cullen KV, Davey RA, Davey MW 2001 Verapamil-stimulated glutathione transport by the multidrug resistance-associated protein (MRP1) in leukaemia cells. Biochem Pharmacol 62:417-424

42. Courtois A, Payen L, Vernhet L, de Vries EG, Guillouzo A, Fardel O 1999 Inhibition of multidrug resistance-associated protein (MRP) activity by rifampicin in human multidrug resistant lung tumor cells. Cancer Lett 139:97-104

43. Tsai C, Ahdab-Barmada M, Daoood M, Watchko JF 2000 P-glycoprotein expression in the developing human central nervous system: cellular and tissue localization. Pediatr Res: 47:436A(abstr)

44. Tsai CE, Daood MJ, Lane RH, Hansen TW, Gruetzmacher EM, Watchko JF 2002 P-glycoprotein expression in mouse brain increases with maturation. Biol Neonate 81:58-64

45. Matsuoka Y, Okazaki M, Kitamura Y, Taniguchi T 1999 Developmental expression of P-glycoprotein (multidrug resistance gene product) in the rat brain. J Neurobiol 39:383-392 